\title{
Study on the Ability of Using Biomass Graphene Sheets Oxide as Superconductive Electronic Storage Devices under Magnetic Force
}

\author{
Wu-Jang Huang \\ Dept. of Environmental Engineering and Science, National Pingtung University of Science and Technology, Pingtung 91201, Taiwan
}

\begin{abstract}
In this paper, a direct magneto-voltaic effect in biomass derived graphene sheets oxide in solution state was observed. 3.0 Volt was detected under a magnetic field of $0.02 \mathrm{~T}$. The possible mechanism of this process has been proposed, that could be attributed to the superconducting effect of biomass graphene sheets oxide under a magnetic field.
\end{abstract}

Key words: Biomass graphene, superconductive, magnetic force.

\section{Introduction}

Graphene is the single layer of graphite, it was just been discovered within 6 six years. Graphene has higher electron conductivity and thermal conductivity than graphite. Currently the usage of graphene in the manufacturing of super-capacitor is very similar with traditional method. This invention demonstrated ability for using graphene oxide solution as electrolytes for super-capacitor and maintains the stored electron current by magnetic force. Therefore we can control the discharging rate of this totally novel biomass derived graphene oxide based super-capacittery pool. In the future we can determine the storage electron-current amount by the used volume of graphene oxide solution rather than the area of electrodes. In our previously publications, we have demonstrated a feasible pathway for preparing graphene sheets carbon materials from biomass derived biochar [1-5]. In this short communication, we would like to report an unpredicted magneto voltaic occurs in biomass derived graphene sheets oxide solution.

Corresponding author: Wu-Jang Huang, Ph.D., professor, research fields: material science, environmental science.

\section{Experimental Section}

Experimental was carried out by homemade biomass derived graphene sheets oxide solution [1], the concentration was $1 \mathrm{wt} \%$ with a transparency light brown color. A homemade wireless charging box was built to provide a homogeneous alternative current magnetic field, from $0 \mathrm{~T}$ to $0.05 \mathrm{~T} .100 \mathrm{~mL}$ of the battled biomass derived graphene sheets oxide solution was placed directly in the center area in the magnetic field for wireless charging for 0 to $30 \mathrm{~min}$, under a magnetic field strength of 0 to $0.02 \mathrm{~T}$. Results are shown in Figs. 1 and 2. Fig. 1 shows the charging curve of biomass derived graphene sheets oxide solution under various charging time. Fig. 2 shows the charging curve of biomass derived graphene sheets oxide solution under various magnetic field.

\section{Discussion}

For the first time, the directly magneto-voltaic effect in biomass derived graphene sheets oxide solution was observed. The $1 \%$ graphene sheets oxide solution is charged by wireless type under low magnetic field $(<0.02 \mathrm{~T})$. The maximum charged voltage is $3.0 \mathrm{~V}$ within $30 \mathrm{~min}$, with a charging rate $0.1 \mathrm{~V} / \mathrm{min}$. Fig. 1 shows the charging curve for 0 to 30 
Electronic Storage Devices under Magnetic Force

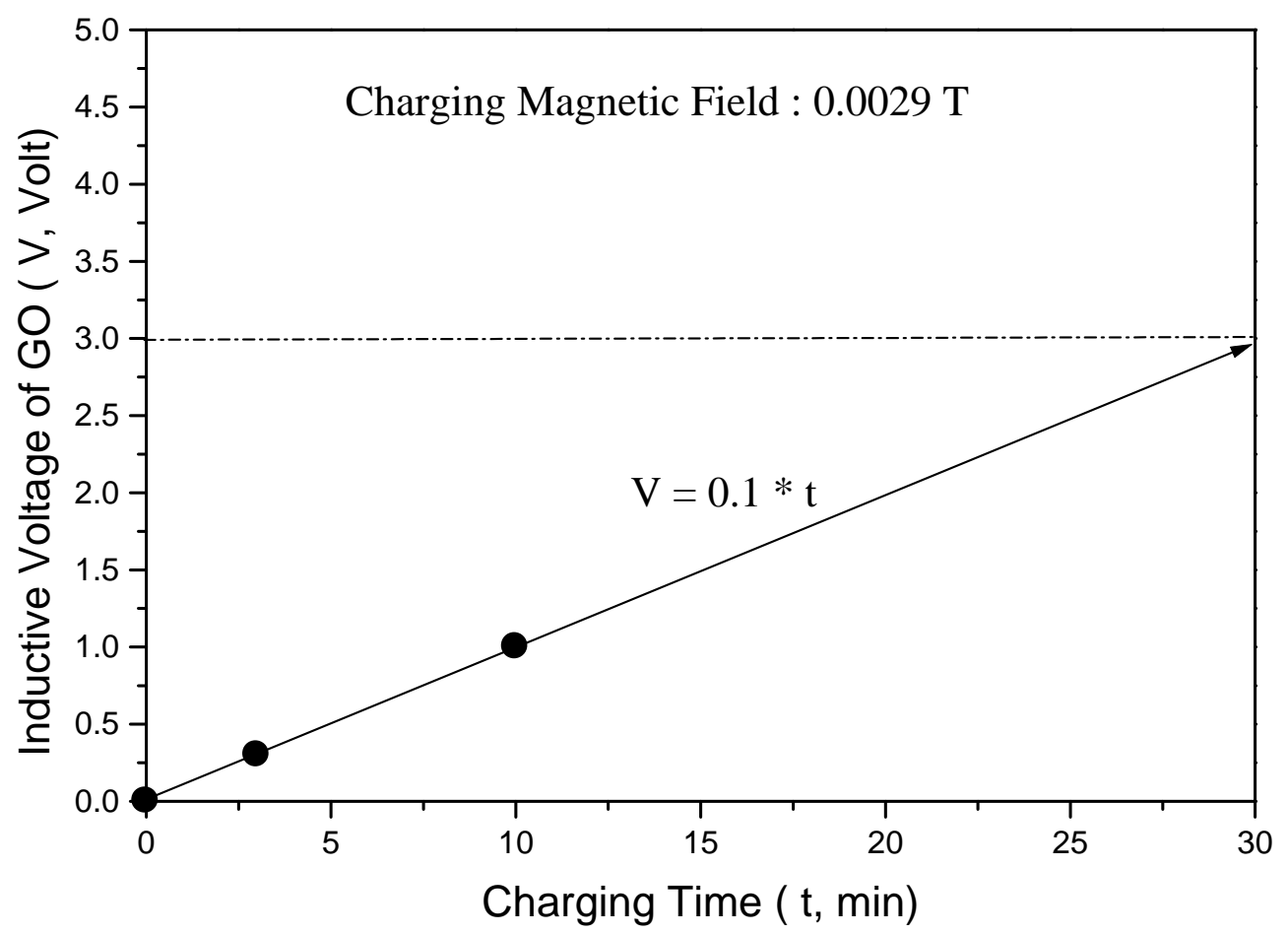

Fig. 1 Charging curve of biomass derived graphene sheets oxide solution under various charging time.

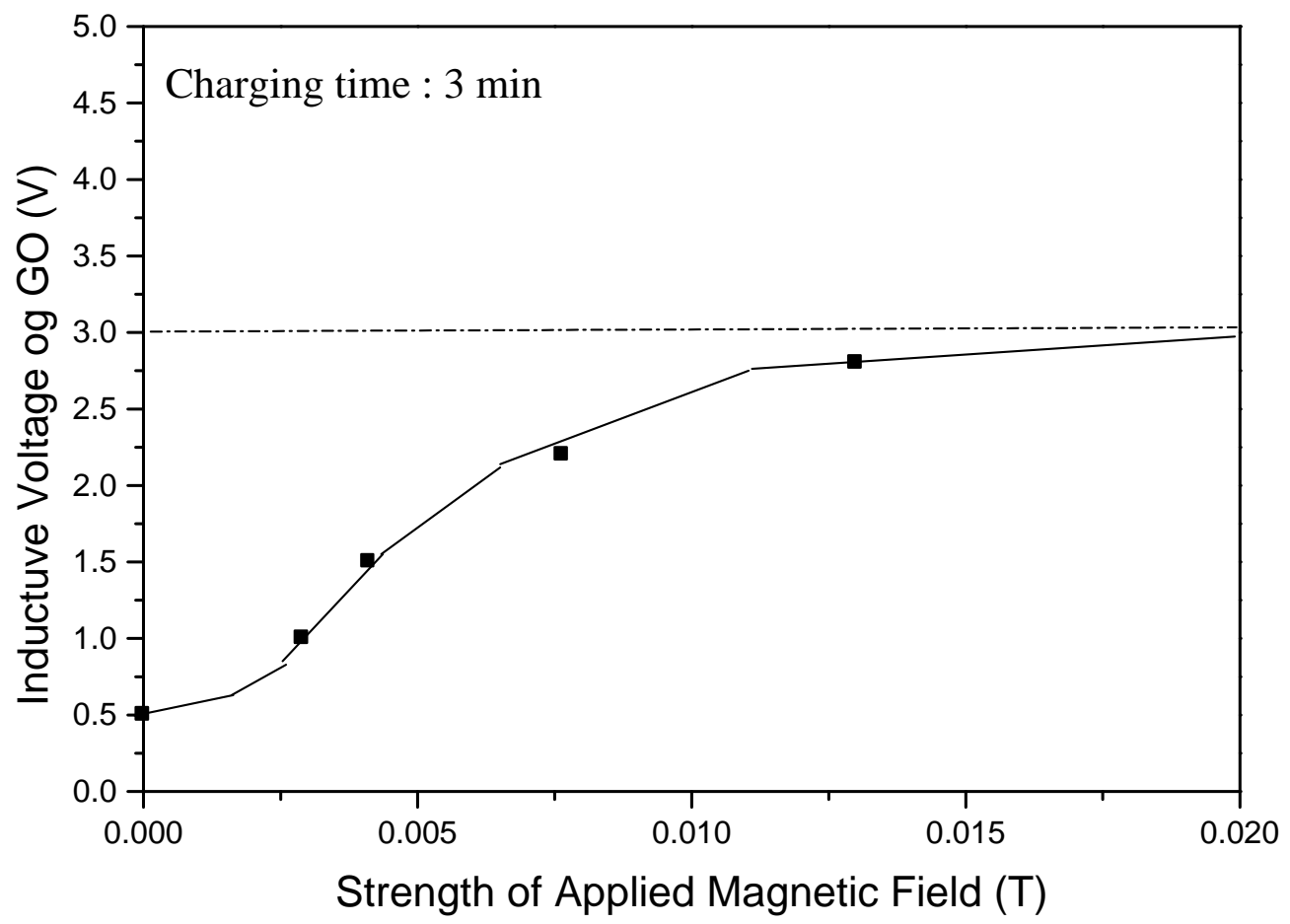

Fig. 2 Charging curve of biomass derived graphene sheets oxide solution under various magnetic field. 
min under $0.0029 \mathrm{~T}$. The maximum voltage of $1.0 \mathrm{~V}$ was measured by a commercial Volta-meter, and the charging rate is $0.1 \mathrm{~V} / \mathrm{min}$. Fig. 2 shows the voltages of charged biomass derived graphene sheets oxide solution under various magnetic field strength. The voltage reaches a maximum was observed and the maximum voltage of $3.0 \mathrm{~V}$ would be approached at magnetic field of $0.02 \mathrm{~T}$. A superconducting storage mechanism of this process is proposed. This invented product is the first demonstration type in the world developed from the idea of the pattern. We predict that the commercial fine product will be produced within future years.

\section{Conclusions}

For the first time, the directly magneto-voltaic effect in biomass derived graphene sheets oxide solution was observed and a superconducting storage mechanism of this process is proposed.

\section{Acknowledgements}

Financial support by National Pingtung University of Science and Technology was fully acknowledged.

\section{References}

[1] Liou, Y.-J., Tsai, B.-D., and Huang, W.-J. 2015. “An Economic Route to Mass Production of Graphene Oxide Solution for Preparing Graphene Oxide Papers.” Materials Science and Engineering B 193 (1): 37-40.

[2] Liou, Y.-J., and Huang, W.-J. 2014. “The Role of Sodium Ions on the Development of Micro-Sized Pores in a High Alpha-Cellulose Content Woody Biomass under Ambient Temperature.” Journal of Cleaner Production 74 (2): 199-201.

[3] Liou, Y.-J., and Huang, W.-J. 2014. "Determination of Graphene Sheets Content in Carbon Materials by Raman Spectroscopy." Journal of the Chinese Chemical Society 61 (5): 1045-8.

[4] Liou, Y.-J., and Huang, W.-J. 2013. "Quantitative Analysis of Graphene Sheet Content in Wood Char Powders during Catalytic Pyrolysis.” Journal of Materials Science \& Technology 29 (5): 406-10.

[5] Milla, O. V., Rivera, E. B., Huang, W.-J., Chien, C.-C., and Wang, Y.-M. 2013. “Agronomic Properties and Characterization of Rice Husk and Wood Biochars and Their Effect on the Growth of Water Spinach in a Field Test.” Journal of Plant Nutrition, and Soil Science I 13 (2): 251-66. 